\title{
The Relationship between Iranian EFL Teachers' Emotional Intelligence and their Teaching Style
}

\author{
Mohammad Ali Ayatollahi ${ }^{{ }^{*}}$ \\ Fatemeh Ferdosi ${ }^{2 * *}$ \\ ${ }^{1}$ Department of English, Sepidan Branch, Islamic Azad University, Sepidan, Iran \\ ${ }^{2}$ Ministry of Education, Shiraz, Iran
}

\begin{abstract}
The present study aimed to detect and compare the most preferred teaching styles by Iranian English teachers in public schools and private language institutes and investigate the possible relationship between EFL teachers' teaching styles and aspects of their emotional intelligence. The participants were $100 \mathrm{EFL}$ teachers from public schools and private language institutes in Iran, Shiraz. The authors used the Persian version of the Bar-On Emotional Quotient Inventory and Grasha's Style Inventory (TSI) to measure the teachers' emotional intelligence and teaching styles, respectively. Formal authority style for EFL teachers of schools and facilitator style for teachers of the private institute were the most preferred teaching styles. In addition, the least preferred styles were 'delegator' and 'formal authority' styles for public school teachers and private institute teachers, respectively. Regarding emotional intelligence, the lowest mean scores were observed in the Stress Management dimension, and the highest was related to the General Mood dimension. Furthermore, 'general mood', as a dimension of emotional intelligence, was highly correlated with 'formal authority' and 'expert style', both of which were public school teachers' preferred styles. Public School teachers were relatively weak at using 'personal model', 'facilitator', and 'delegator' teaching styles. Thus, it is recommended that they adapt themselves to these styles.
\end{abstract}

Article Information

Received 30 June 2021

Accepted 21 July 2021

Published August 14, 2021

Keywords: EFL teachers, stress management, general mood

\section{Introduction}

Teaching styles are the behaviors that a teacher exhibits in his or her professional activity. They encompass not just the strategies and procedures used in the classroom but also the rhetoric they use. English is taught in both public schools and private language institutes in Iran. However,

*Corresponding Author: Mohammad Ali Ayatollahi (ayatollahi1345@gmail.com), Mahtab 8, No. 17, Beheshti District, Shiraz, Iran, 7189658187 many language learners feel that there is a big difference between the effectiveness of English courses taught in schools and those taught in private language institutes. Thus, dissatisfied with the way they are taught in schools, a great number of language learners enroll in language institutes. Hence, understanding differences in teachers' teaching styles may be insightful. The authors also investigated whether differences in teaching styles are related to emotional intelligence. The objective of this study was two-fold: a) to compare the most preferred 
teaching styles by Iranian EFL teachers in public schools and private language institutes and b) to investigate the possible relationship between teachers' teaching styles and their emotional intelligence.

\section{Teaching Styles}

Each individual possesses a distinct type or style of thinking, preferences, and ways of doing things. Style is the personal way of acting, of behaving. The concept of teaching style is useful in understanding and explaining the teaching-learning process. Although there is no one ideal style of teaching that one should strive to master, there are relatively appropriate styles depending on various individual and institutional variables. The concept of "style" seems to be more operational rather than more extensive or more restrictive classical concepts such as methods, systems, techniques, attitudes, and skills.

Teaching styles are teachers' way of establishing the relation with the pupils, of managing a class or a learning group, without prejudging the methods or the techniques implemented (strategies). In academic and educational contexts, teaching styles refer to the instructors' characteristics and attitudes which they utilize in their teaching process. Jarvis (2004) considered teaching style as "the implementation of philosophy; it contains evidence of beliefs about values related to and attitudes toward all the elements of the teaching-learning exchange" (p.40). This definition indicated that teachers used certain teaching techniques, activities, and approaches in teaching in the classroom (Cooper, 2001). In other words, teachers' teaching styles are directly correlated with teachers' teaching behavior in the classroom. Teaching is an emotional performance that mirrors teachers' thoughts and the proceedings in which those thoughts are implanted (Hargreaves, 1998). In other words, teachers' teaching styles are affected by their emotions; thus, emotional intelligence and teaching styles are related.

According to Westwood (2008), teaching models represent the most general level of education. Each represents a philosophical orientation of teaching. The strategies represent the set of methods and approaches, which will determine the choices of techniques, materials, and educational situations concerning the object and the goal of learning. Westwood (2008) identifies three main teaching models, namely, the demonstrative model, the interrogative model, and the active model. The demonstrative method is particularly suited to the transmission of physical and manual knowhow. This method follows the following sequence: show (demonstration); get people to do (experimentation); make people say (reformulation). In the Interrogative method, with the help of appropriate questioning, the teacher allows the student to build his knowledge on his own. In the active methods, trainees only learn through their activity, observation, reflection, experimentation, and personal activities. In addition, the organization and conduct of training are not based on constraints, but they develop from the real and evolving motivations of the trainees. Grasha (1996) defined teaching styles as particular patterns of needs, beliefs, and behaviors that teachers display in the classroom. Some believe classes should be 
teacher-centered, where the teacher is an expert and authority in presenting the information. Others take a learner-centered approach, viewing their role mostly as a facilitator of student learning. According to Grasha (1996), teaching styles will affect how teachers present information, interact with students, supervise coursework, and ultimately evaluate students' success.

Lippitt and White (cited in Palmer, 1998) refer to three teaching styles, namely the autocratic style, the democratic style, and the laissez-faire style. The autocratic teachers themselves decide for all the activities or tasks to be carried out; that is, they are interested in making all the decisions, organizing and distributing all the activities, remaining distant from the group in their realization, and evaluating individually. The democratic teachers are those who care to plan according to the members of the group, encourage the group of students to discuss, decide, schedule, and distribute activities. The third style is called laissez-faire: these teachers are mostly characterized by not participating, staying out as much as possible, and leaving the initiative to the students..

Therer and Willemart (1982) attempted to identify and describe four teaching styles representative of observable teaching practices. These styles are defined based on a two-dimensional model which combines two attitudes of the teacher: attitude towards the subject and attitude towards the learners. Each of these attitudes is expressed in varying degrees, weak or strong, and disinterest or interest. The combination of these two attitudes identifies four basic styles, namely, transitive, incentive, associative, and permissive. The transitive style is more material-centered; the incentive style is centered both on the subject and on the learners; the associative style is more focused on learners; the permissive style is very little centered on either the learners or the subject. In addition, Therer and Willemart (1983) hypothesize that each of these four styles may be effective or ineffective depending on the situation and the extent and degree of teacher's or trainer's interventions. There is, therefore, no such thing as a "good style" that is valid in all circumstances.

Anderson (cited in Palmer, 1998) proposes two styles, namely dominator and integrator. A dominator teacher is fundamentally an authoritarian person who normally uses demanding mandates and provisions, imposes orders by force, and does not accept or consider students' autonomous decisions. The integrative teacher can create a friendly social climate where there is recognition and praise, not violence; he/she creates an environment where criticism is constructive and objective, and considers the students' personal information.

Gordon (cited in Palmer, 1998) hypothesizes that a teaching style is more conditioned by school groups and the education system than by the teachers. He distinguishes three types of teaching styles: instrumental, expressive, and expressiveinstrumental; the instrumental style is typical of the teachers who guide their activity according to learning objectives and focus on direction and authority. The expressive style is aimed at satisfying the affective needs of students; the teacher cares, above all, to satisfy the students with their performance 
and social relationships. The expressiveinstrumental style is a mixture of both and is typical of the teachers who intend to combine an interest in teaching with their concern for the students' needs.

By capturing the influence generated by the verbal behavior of the teacher in the classroom climate and the performance of the students, Flanders (1984) identified two types of teaching styles, namely direct and indirect. The direct style consists of exposing one's ideas, and imposing one's authority and competence. The indirect style is typical of teachers who take into account the ideas of their students, promote dialogue and influence the students' feelings.

Bennett (cited in Palmer, 1998) stated that the aforementioned typologies have several shortcomings, such as bias, ambiguity, and dichotomy. This author elaborated a typology, which in his opinion, is global, precise, and complete. Progressive or liberal style is located at one extreme, where teachers are considered those whose classroom behavior reflects characteristics such as disciplinary integration, intrinsic motivation, flexible grouping, student's choice of work, and a certain disregard for class control and performance. Concerning aspects directly related to teaching methods, accepting the advantages of formal methods for acquiring basic knowledge and structuring learning environments leads to less disorientation of the student. However, they reject the formal style used by their peers to achieve selfdiscipline, personal development of the student, the balance between individual and collective work, and the greater demands that the work of teachers entails. Traditional or formal styles are at the other extreme and have characteristics opposite to the previous ones: extrinsic motivation, minimal choice of work by the student, grouping fixed (total class and individual work), and concern for performance control. Mixed styles are between one extreme and the other; they are the product of the combination of both styles to a different degree.

Grasha (1996) identified five teaching styles, namely expert (They transmit information), formal authority (They set standards), personal model (They teach by direct examples), facilitator (They guide by asking questions and exploring options), and delegator (They develop students' ability to function autonomously). Expert instructors possess the knowledge and expertise that students need. They strive to maintain status as an expert among students by displaying detailed knowledge and by challenging students to enhance their competence. Instructors with formal authority style possess status among students because of knowledge and role as faculty members. They are concerned with the standard ways to do things and provide students with the structure they need to learn. Instructors with a personal model teaching style believe in teaching by personal example. They establish a prototype for how to think and how to behave. Instructors with facilitator style emphasize the personal nature of teacher-student interactions. Their overall goal is to develop the capacity for independent action, initiative, and responsibility in students. The instructors with the delegator style are concerned with developing students' capacity to function autonomously; so that, the students can work 
independently on projects or as part of autonomous teams.

Defining learning styles as the preferences of each student, Grasha (2003) believes there is a relationship between teaching styles and learning styles. He argues that teachers' way of thinking and their interaction with the rest of the students in different environments and educational experiences form the basis for students to generate knowledge regarding specific content. According to Grasha (2003), each student has different needs and learning styles that affect how they achieve knowledge and how they interact with other people. Teachers' interaction with students can shape and support the way students adopt themselves, choosing different learning styles (Grasha, 2002). The integration of these two areas, teaching styles and learning styles are essential for effective education (Alumran, 2008; Cano, 2000). These preferences show the academic experiences that the student body has. According to Grasha (2001), learning styles are considered part of the teaching philosophy since they provide a reason for the implementation of a variety of strategies during instruction to satisfy learning needs (Alonso and Gallego, 2010). This process could favor learning, helping to dispel incompatibilities between teaching styles and learning styles, leading to greater effectiveness in the training activity (Hervás, 2003).

\section{Teaching as an emotional endeavor}

Researchers (Hargreaves, 1998; Hargreaves \& Tucker, 1991) insist that teaching is an emotional endeavor. According to Hargreaves (1998), an emotional behavior triggers the processes by which thoughts are provoked. Daniel Goleman (1995) defines emotional intelligence as being able to maintain motivation and perseverance under frustration, controlling one's impulses, delaying personal satisfaction, maintaining regular moods, and preventing trouble from negatively affecting one's judgment, perseverance, and hopefulness. Goleman (1995) listed the primary emotions like anger (resentment, fury, irritability, indignation, exasperation, animosity), sorrow (sadness, being upset, melancholy, loneliness, self-pity, sulk), fear (nervousness, anxiety, being afraid, terror, concern, worry, horror, misunderstanding), joy (relief, happiness, blessing, pride, pleasure, euphoria, satisfaction, amusement, contentment), love (friendship, trust, acceptance, commitment, awe, worship, kindness, affinity), surprise (wonder, shock), disgust (contempt, detestation, revulsion, repugnance), and shame (embarrassment, guilt, humiliation, regret, remorse).

Emotional intelligence mixes two notions that are usually opposed. On the one hand, the word "intelligence" designates the capacity for reasoning and analysis, and on the other hand, the word "emotion" designates the primary reactions that are difficult to control and occur following the occurrence of a well-known event. This concept has been talked about since the 80s, and credible quantitative scientific studies have been carried out since the 90 s.

Salovey and Meyer (1990) were the first to use and conceptualize the term "El". For them, $\mathrm{El}$ is at the intersection of cognition and emotions. They argue that individuals vary in their ability to process information of an emotional nature and to relate this emotional 
processing to general cognition. People with high emotional intelligence can assess and express emotions (their own and those of others), regulate them, and know how to use them to facilitate cognitive processes. The authors then revised their model and now propose a more complex framework in which $\mathrm{El}$ is a hierarchical construct with four branches. Each of these branches represents a category of capacities, namely the perception and assessment, verbal and non-verbal, of emotions, the ability to integrate and assimilate emotions to facilitate and improve cognitive and perceptual processes, knowledge of emotions, understanding of their mechanisms, their causes, and their consequences, and managing one's emotions and those of others.

Goleman (1995) proposed his model of "emotional intelligence" based on 25 subskills which revolve around five main axes, namely self-awareness or the ability to understand one's emotions, self-regulation or self-control, intrinsic motivation, empathy, and social skills. Self-awareness refers to the ability to recognize and understand personal moods, emotions, and internal drivers and their effect on others. Indicators of self-awareness include self-assurance, realistic self-report, and a sense of humor. Self-awareness depends on the ability to monitor one's own emotional state and correctly identify and name one's emotions. Self-regulation refers to the ability to control or redirect disruptive impulses and moods and the tendency to suspend judgment and think before acting. Indicators include reliability and integrity, as well as acceptance of ambiguity and openness to change. Intrinsic motivation is an internal engine that goes beyond money and statusthat are both considered external rewards. Intrinsic motivation connects with what is important in life, the pleasure of doing a task, the curiosity to learn, a flux that comes from immersion in an activity, and a tendency to pursue goals with energy and persistence. Indicators include a strong desire for accomplishment, optimism, and organizational commitment. Empathy refers to the ability to understand the emotional structure of others, and the ability to treat people based on their emotional reactions. The indicators include expertise in building and maintaining talent and crosscultural sensitivity. Empathy is about interest in and involvement in the emotions of others, the ability to sense what they are feeling. Social skill refers to the ability to manage relationships and build networks, as well as an ability to find commonalities and build relationships. Indicators of social skills include effectiveness in leading change, persuasive power, building expertise, and team leadership. Goleman (1995) acknowledges that he has moved from El to something much larger. In his book, he writes that there is an old word to represent the skill set of emotional intelligence, i.e., character.

Director of the Danish Institute of Applied Intelligence, Bar-On (1997), developed one of the first measures of $\mathrm{El}$ using the term "emotional quotient", called the Bar-On model. He defines El as a set of skills, competencies, and non-cognitive skills that influence an individual's ability to succeed by adapting to the pressures and demands of their environment. Five components, divided into 15 sub-dimensions, constitute this model, namely intrapersonal skills, interpersonal skills, 
adaptability, stress management, and the general mood. According to Bar-On, emotional intelligence develops over time and can be improved through training and therapy. BarOn (2000) speaks of "emotional and social intelligence" to encompass his concept and redefines his model in 10 key components and five facilitators of El (optimism, joy, selfdevelopment, independence, and social responsibility). Bar-On hypothesizes that people with above-average EQ are generally more successful in coping with the demands and pressures of the environment. Like Goleman, he adds that an El disability can prevent success and reflect the existence of psychological problems. In general, he finds that $\mathrm{El}$ and general intelligence both contribute equally to a person's general intelligence, which is an indication of their potential to be successful in life.

The last two models from Goleman and Bar-On are similar to the BIG FIVE models (also called "FFM": Five-Factor Model), which describes the personality according to five fundamental character traits, namely, openness, conscientiousness, extraversion, empathy, and emotional stability. Openness refers to traits, such as how an inclined person is to conform to societal or cultural norms, how concretely or abstractly someone thinks about things, and how an open or resistant person is to change. A person who is a creative thinker and always looking for ways to do things better might score high on measures of openness. Conscientiousness has to do with a person's degree of organization, level of discipline, and how prone he or she is to take risks. A college student who never misses a class and has a GPA of 4.0 would probably prove to have a high degree of conscientiousness as measured on a personality assessment. Extraversion is a personality characteristic that describes things like how social a person is or how warm and loving they tend to be. Extraverts are people who would typically prefer to go out to a party with lots of friends instead of staying in and watching a movie with one or two friends. The Big Five traits have been subjected to rigorous testing over the past several decades. The research continues to support the notion that we all possess each of the five personality characteristics to some degree. Moreover, even though we share only five common personality traits, the possible combinations, or personality types, are endless when considering each trait's varying degrees. For example, not all of us are equally agreeable or neurotic.

The following research questions were propounded for the current study. The first question is what teaching styles of Iranian EFL teachers teaching are the preferred in public and private sectors while the second research questions is whether there is any significant relationship between Iranian EFL teachers' emotional intelligence (El) and their teaching style.

\section{Method}

\section{Participants}

A sample of 100 teachers participated in this study, comprising 67 females and 33 males aged 22 to $49(M=33.47, S D=7.64)$. All of the participants were EFL teachers teaching English in Shiraz public schools and private institutes. Attempts were made to include teachers from different age groups, with 
different years of teaching experience, and of both genders to ensure generalizability. The participants were $70 \mathrm{EFL}$ high school and 30 private institute teachers selected according to convenience sampling method from among EFL teachers teaching English at high schools and intermediate or upper-intermediate levels at different institutes in Shiraz. The researcher tried to select the participants from all educational districts in the city of Shiraz, Iran. The participant's level of education differed from Associate of Arts (AA) to Master of Art (MA). Eighteen participants had AA, 32 Bachelor of Arts (BA), and $54 \mathrm{MA}$, and 3 were Ph.D. candidates. Among them, 67 had majored in English language teaching, 22 in English translation, nine in English literature, and one in linguistics.

\section{Instrument}

\section{Emotional Intelligence Questionnaire (Bar-On Emotional Quotient Inventory)}

The authors employed The Persian translation of the Bar-On Emotional Quotient Inventory (Bar-On, 1997) to measure the teachers' emotional intelligence. It consisted of five basic skills as follows: the interpersonal component with 30 statements, the interpersonal component with 18 items, the adaptability component with 18 statements, the stress management component with 12 statements, and the general mood component with 12 statements. The subcomponents of the intrapersonal component were selfawareness (6 items), assertiveness ( 6 items), self-regard (6 items), self-actualization (6 items), and independence (6 items). The subcomponents of the interpersonal component were empathy (6 items), interpersonal relationship (6 items), and social responsibilities (6 items). The subcomponents of the adaptability component were problemsolving ( 6 items), reality testing (6 items), and flexibility (6 items). The subcomponents of stress management were stress tolerance $(6$ items) and impulse control (6 items). The subcomponents of general mood were happiness (6 items) and optimism (6 items). The Cronbach's Alpha reliability index was reported as 80 (Moslehi, Samouei, Tayebani, $\&$ Kolahduz, 2015). The Persian version has an acceptable internal consistency, test-retest reliability. Cronbach's alpha coefficient for the test was found to be .76, and the results of the factor analysis provided convincing support for the inventory hypothesized structure or construct validity (Moafian, \& Ghanizadeh, 2009). Items in the original questionnaire were translated into Farsi by a native speaker of Farsi. Then, the questionnaire was backtranslated into English by a different native speaker of Farsi. After careful comparison of the English back-translation and the original English items, the Farsi translations of several items were revised and double-checked again by a third speaker of Farsi for translation accuracy.

\section{Teaching Styles Questionnaire (Grasha's Teaching Styles Inventory)}

The authors administered the 40statement Teaching Styles Inventory, developed by Grasha (1996) to the participants. Each item was scored using a 7point Likert scale from 1 (strongly disagree) to 7 (strongly agree). The questionnaire required the participants to respond to each of the items in terms of how they teach. Every eight items identified one of the five basic teaching 
styles, namely expert, formal authority, personal model, facilitator, and delegator. Mean score ranges for every group of items related to the individual teaching styles were calculated. Then, the mean scores were categorized as low, moderate, or high based on the standards developed by Grasha (1996). Regarding this instrument, Grasha (1996) reported acceptable reliability (alpha $=0.68$ 0.75 on individual scales, and alpha $=0.72$ for the entire test).

\section{Data Collection Procedure}

The authors administered the Bar-On questionnaire and teaching styles inventory to 100 Iranian EFL teachers who taught English in public schools and private institutes in high schools and private language institutes. The questionnaires were administered in two sessions. First, the Bar-On questionnaire was administered to EFL teachers. They had two days to complete it. Then, the authors distributed teaching styles inventory among the participants to complete in two days.

The authors coded the questionnaires numerically, and assured the participants that their views would be confidential. As an incentive, the participants could request to receive feedback about their performance on the instruments by presenting their codes.

\section{Data Analysis}

The authors entered the data collected from the surveys into the software called Statistical Package for Social Sciences (SPSS) version 23 to perform descriptive and inferential statistics. Descriptive statistics were used to summarize the characteristics of the variables including number of the participants, mean, and standard deviation. . A Pearsonproduct moment correlation coefficient was employed to determine if any significant relationship exists between Iranian EFL teachers' emotional intelligence and their teaching styles.

\section{Findings and Discussion}

\section{Findings}

\section{Teaching style preferences of Iranian EFL teachers}

The first objective of this study was to investigate the teaching style preferences of EFL teachers in schools and institutes. The authors used descriptive statistics to identify the teaching style preferences of EFL teachers in public schools and private institutes. Mean, standard deviation, minimum and maximum values were reported.

\section{Table 1}

Descriptive Statistics for Teaching Style Preferences of EFL teachers of schools and institutes

\begin{tabular}{lllll}
\hline \multirow{2}{*}{ Teaching Styles Subscales } & \multicolumn{2}{l}{ Schools } & \multicolumn{3}{l}{ Private Institutes } \\
\cline { 2 - 5 } & Mean & SD & Mean & SD \\
\hline Expert & 4.74 & 1.14 & 3.97 & .94 \\
Formal Authority & 5.32 & 1.31 & 3.66 & .84 \\
Personal Model & 4.51 & 1.11 & 4.95 & 1.02 \\
Facilitator & 4.02 & .99 & 5.65 & 1.23 \\
Delegator & 3.45 & .86 & 4.67 & 1.17 \\
\hline
\end{tabular}


According to table 1, for EFL teachers teaching at public schools, formal authority style has the highest mean score $(M=5.32$, $S D=1.31)$ followed by expert style $(M=4.47$, $S D=1.14)$, Personal model $(M=4.51, S D=1.11)$, Facilitator ( $M=4.02, S D=.99)$, and delegator $(M=$ $3.45, \mathrm{SD}=.86)$. As the above table signifies, for the teachers teaching English at private institutes, facilitator style has the highest mean score $(M=5.65, S D=1.23)$ followed by personal model style $(M=4.95, S D=1.02)$, delegator style $(M=4.67, S D=1.17)$, Expert style $(M=3.97, S D=$ $.94)$ and formal authority styles $(\mathrm{M}=3.66, \mathrm{SD}=$ .84).

Table 2

Descriptive Statistics (Dominant Teaching Style)

\begin{tabular}{lcccccc}
\hline \multirow{2}{*}{ Teaching Styles } & \multicolumn{7}{l}{ Schools } & \multicolumn{5}{l}{ Institutes } \\
\cline { 2 - 7 } & Frequency & Percent & $\begin{array}{l}\text { Cumulative } \\
\text { Percent }\end{array}$ & Frequency & Percent & $\begin{array}{l}\text { Cumulative } \\
\text { Percent }\end{array}$ \\
\hline Expert & 12 & 17.1 & 17.4 & 2 & 6.7 & 6.7 \\
Formal Authority & 53 & 75.7 & 94.2 & 0 & 0 & 0 \\
Personal Model & 2 & 2.9 & 97.1 & 7 & 23.3 & 30.0 \\
Facilitator & 1 & 1.4 & 98.6 & 19 & 63.3 & 93.3 \\
Delegator & 1 & 1.4 & 100.0 & 2 & 6.7 & 100.0 \\
Total & 70 & & & 30 & 100.0 & \\
\hline
\end{tabular}

To investigate the teaching style preferences of Iranian EFL teachers, the percentage and frequency of each teaching style subscale were calculated for both the teachers teaching at public schools and private language institutes. As table 2 demonstrates, the highest percentage is related to formal authority (75.7\%) for school teachers and facilitator style (63.3\%) for institute teachers. Expert style (17.1\%) gets the second-highest percentage of school teachers and personal model style (23.3\%) for institute teachers. The data are presented visually in the following bar chart.

\section{Relationship between Iranian EFL teachers' teaching styles and emotional intelligence}

The second objective of this study was to investigate the relationship between emotional intelligence and teaching styles. To this end, the following null hypothesis was formulated. HO: There is no relationship between Iranian EFL teachers' teaching styles and emotional intelligence. The authors used descriptive statistics to identify teachers' profile of emotional intelligence attributes. The results are presented in the following table.

Table 3

Descriptive Statistics (Dominant Teaching Style)

\begin{tabular}{llll}
\hline Teaching Style & $\mathrm{N}$ & Mean & Std. Deviation \\
\hline General Mood & 100 & 4.07 & .92 \\
Intrapersonal & 100 & 3.69 & 1.02 \\
Interpersonal & 100 & 3.71 & 1.05
\end{tabular}




\begin{tabular}{llll} 
Adaptability & 100 & 3.54 & 1.07 \\
Stress Management & 100 & 3.24 & 1.13 \\
Total & 100 & 3.65 & .85 \\
\hline
\end{tabular}

As table 3 demonstrates, the lowest mean score of EQ-i was observed in the stress management subscale $(M=3.24, S D=1.13)$, and the highest was related to general mood subscales $(\mathrm{M}=4.07, \mathrm{SD}=.92)$. In general, the total mean scores on all subscales of the EQ $(\mathrm{M}=3.56, \mathrm{SD}=.85)$ shows that the teacher participants scored high on each subscale of the emotional intelligence.

\section{The Relationship between Teaching Style and Emotional Intelligence}

To find out the relationship between different teaching styles and emotional intelligence subscale, Pearson productmoment correlation coefficients were obtained after checking the test assumptions. The results are summarized in Table 4.

\section{Table 4}

Correlation matrix of the subscale of EQ-I and teaching style measures

\begin{tabular}{lllllll}
\hline Teaching Style & & Intra. & Inter. & Ad. & Sm. & Gm. \\
\hline Expert & Pearson & $.231^{*}$ & .163 & .102 & .133 & $.339^{*}$ \\
& Correlation & & & & & \\
& Sig. (2.-tailed) & .021 & .105 & .312 & .186 & .001 \\
& $\mathrm{~N}$ & 100 & 100 & 100 & 100 & 100 \\
Formal Authority & Pearson & .190 & .183 & .058 & .070 & $.342^{* *}$ \\
& Correlation & & & & & \\
& Sig. (2.-tailed) & .059 & .069 & .568 & .488 & .000 \\
& $\mathrm{~N}$ & 100 & 100 & 100 & 100 & 100 \\
Personal Model & Pearson & .143 & .072 & .045 & $.241^{*}$ & .145 \\
& Correlation & & & & & \\
& Sig. (2.-tailed) & .156 & .474 & .656 & .016 & .151 \\
& $\mathrm{~N}$ & 100 & 100 & 100 & 100 & 100 \\
Facilitator & Pearson & .023 & .042 & .010 & .138 & .024 \\
& Correlation & & & & & \\
& Sig. (2.-tailed) & .819 & .675 & .918 & .171 & .815 \\
& $\mathrm{~N}$ & 100 & 100 & 100 & 100 & 100 \\
Delegator & Pearson & .058 & .014 & .053 & .174 & .077 \\
& Correlation & & & & & \\
& Sig. (2.-tailed) & .569 & .889 & .602 & .083 & .446 \\
& $\mathrm{~N}$ & 100 & 100 & 100 & 100 & 100 \\
\hline
\end{tabular}

Intra.=Intrapersonal; Inter.=Interpersonal, Ad.=Adaptability; S=Stress management, Gm.=General mood

As the above table reveals, significant correlations between the components of both measures were found. The highest correlations were found between formal authority and 
general mood $\left(r=0.34,{ }^{* *} p<.01, \mathrm{n}=100\right)$, expert and general mood $\left(r=0.33,{ }^{* *} p<.01, n=\right.$ 100).

\section{Discussion}

\section{Restatement of research question one}

The first research question is related to the teaching style preference of Iranian EFL teachers as follows. The first research question is what the preferred teaching styles of Iranian EFL teachers' teaching are in public and private sectors.

EFL teachers of public schools mostly preferred formal authority style and expert style, while EFL teachers of private language institutes preferred to use facilitator style and personal model style in their teaching. The findings related to the private sector's teaching style are confirmed by Heydarnejad, Hosseini Fatemi, and Ghonosooly's (2017). Their results indicated that Iranian EFL teachers preferred facilitator and delegator followed by personal model, expert, and formal authority. In addition, the findings of the public sector's teaching style were confirmed by Amini, Samani, \& Lotfi (2012), in which the expert style was the dominant style in the Iranian context. Working in different academic settings may be the reason for the difference between public and private sectors (Ghanizadeh \& Heydarnejad, 2015; Ghonosooly, Khajavy, \& Asadpour, 2012). English learning curriculum at schools in Iran is derived from the combination of the Grammar translation method and Audiolingualism, while in private institutes, communicative language teaching is followed.

\section{Restatement of research question two}

To answer the second research question, the authors utilized Pearson product-moment correlation coefficients. Based on the results of table 4, there was a significant correlation between the components of emotional intelligence and teaching style. The highest correlation was found between 'formal authority' and 'general mood', and between 'expert' and 'general mood'. Therefore, the null hypothesis, i.e., "there is not any significant relationship between Iranian EFL teachers' emotional intelligence (EI) and their teaching style" was rejected. The results are in line with the study conducted by Mousapour, Negari \& Khorram(2015), who concluded that some components of emotional intelligence could predict Iranian EFL teachers' teaching style. They also revealed a significant relationship between the teachers' emotional intelligence and their teaching styles. Goetz et al. (2013) and Heydarnejad, Hosseini Fatemi, and Ghonosooly (2017) also confirmed the relationship between teachers' emotions and teachers' styles. Similar results were reported by Shatalebi, Sharifi, and Javadi (2011), who examined the relationship between components of emotional intelligence and learning styles. They found that some components of emotional intelligence were correlated with some learning styles and individual preferences.

\section{Conclusion}

The present study investigated the preferred teaching styles and $\mathrm{El}$ of EFL teachers. In addition, it investigated if there was any statistically significant relationship between Iranian EFL teachers' $\mathrm{El}$ and their 
teaching styles. The preferred teaching styles were declared, and their subcomponents were explored. The findings of this study revealed that there was a significant relationship between the teachers' emotional intelligence and their teaching styles. According to the results, the highest correlations were found between formal authority and expert styles, and general mood. Based on the results reported above and the scope of this study, considering limitations and delimitations of the present study, some pedagogical implications can be made as to the following: Personalityrelated traits are not fixed, but they are modifiable and can be developed. Then, policymakers can work on translators' personality traits to enhance their teaching quality. The strong relationship between emotional intelligence and teachers' teaching styles implies that emotional intelligence needs to be emphasized to enhance teachers' self-awareness and awareness of others.

\section{References}

Alonso, C. and Gallego, D. (2010). Learning styles as competencies for study, work, and life. Learning Styles Magazine, 6 (6), 4-22. Retrieved from http://learningstyles.uvu.edu/index.php/ils Larticle/view/128/89

Alumran, J. I. A. (2008). Learning styles in relation to gender, field of study, and academic achievement for Bahraini University Students. Individual Differences Research, 6(4), 303-316.

Anderson, L. E. y Carta-Falsa, J. (2002). Factors that make faculty and student relationships effective. The College Teacher, 50(4), 134138. doi: $10.1080 / 87567550209595894$
Amini, M., Samani, S., \& Lotfi, F (2012). Reviewing Grasha teaching methods among faculty members of shiraz medical school. Research and Development in Medical Education, 1(2), 37-43.

Bar-On, R (1997). Bar-On Emotional Quotient Inventory (EQ-i): Technical Manual. Toronto, Canada: Multi- Health Systems.

Cano, F. (2000). Gender differences in learning strategies and styles. Psicothema 12 (3), 360-367. Retrieved from http://www.redalyc.org/articulo.oa?id=72 712306

Cooper, T. C. (2001). Foreign language teaching style and personality. Foreign Language Annals, 34, 301-317.doi: 10. 1111/j.19449720. 2001. Tb 0206.x

Dehshiri, R. (2003). The Reliability and validity of EQ-I in Iran context. Unpublished master. S thesis, Allame Tabatabai University, Tehran, Iran.

Ghanizadeh, A., Heydarnejad, T. (2015). A crosscontextual analysis of Iranian EFL teachers' attitudes and perceptions of critical thinking. International Journal of Research Studies in Education, 4(4), 27-38.

Goleman, D. (1995). Emotional intelligence. Bantam Books.

Grasha, A. F. (1996). Teaching with style. A practical guide to enhancing learning by understanding teaching and learning styles https://www.academia.edu/6211237/Tea ching With Style by Dr. Grasha

Grasha, A. F. (2002). Teaching with style: Enhancing learning by understanding teaching and learning styles: International Alliance of Teacher Scholars.

Ghonsooly, B., Khajavi, G. H., \& Asadpour, S. F. (2012). Willingness to communicate in 
English among Iranian non- English major university students. Journal of Language and Social Psychology, 31, 197-211.

Goetz, T. Ludtke, O., Nett, U.E., Keller, M., \& Lipnevich, A. (2013). Characteristics of teaching and students' emotions in the classroom: Investigating differences across domains. Contemporary Educational Psychology, 38(4), 383-394.

Goleman, D. (1995). Emotional Intelligence. McGraw-Hill.

Grasha, A.F. (1996). Teaching with style: A practical guide to enhancing learning by understanding teaching and learning style. Alliance Publishers.

Hargreaves, A. (1998). The emotional practice of teaching. Teaching and Teacher Education, 14(8), 835-854.

Hargreaves, A., \& Tucher, E. (1991). Teaching and guilt: Exploring the feelings of teaching. Teaching \& Teacher Education, 7(5-6), 491505.http://dx.doi.org/10.1016/0742-051X (91)90044-P

Hervás, R. M. (2003). Teaching and learning styles in educational settings. Grupo Editorial Universitario.

Heydarnejad, T., Hossini Fatemi, A., \& Ghonsooly, B. (2017). An Exploration of EFL Teachers' teaching styles and emotions. Journal of Applied Linguistics and Language Research, 4(2), 26-46.

Jarvis, P. (2004). Adult education and lifelong learning: Theory and practice. Routledge Falmer.

Palmer, P.J. (1998). The courage to teach: Exploring the inner landscape of teacher's lives. Jossey-Bass.
Mayer, J. D., Salovey, P., \& Caruso, D. R. (2002). Mayer-Salovey-Caruso Emotional Intelligence Test (MSCEIT) User's Manual. MHS Publishers.

Moafian, F., \& Ghanizadeh, A. (2009). The relationship between Iranian EFL teachers' emotional intelligence and their selfefficacy in Language Institutes. System, 37(4), 708-718.

Moslehi, M., Samouei, R., Tayebani, T., \& Kolahduz, S. (2015). A study of the academic performance of medical students in the comprehensive examination of the basic sciences according to the indices of emotional intelligence and educational status. Journal of education and health promotion, 4 (1), 66-80.

Mousapour Negari, G., \& Khorram, A. (2015). The relationship between Iranian EFL teachers' emotional intelligence and their teaching styles. International Journal of Research Studies in Language Learning, 4(4),3-14.

Salovey, P., \& Mayer, J. D. (1990). Emotional intelligence. Imagination, cognition, and personality, 9(3), 185-211.

Samouie, R. (2002). Interpreting and analyzing Bar-On EQ inventory. Journal of Sina Research Center, 6(2), 1-10.

Shatalebi, B., Sharifi, S., Saeedian, N. \& Javadi, H. (2011). Examining the Relationship between Emotional Intelligence and Learning Styles. Journal for Social and Behavioral Sciences, 31, 95-99 doi: 10.1016/j.sbspro.2011.12.022.

Therer and Willemart (1982). Encyclopedia of evaluation. Liège University.

Therer, J., \& Willemart, C. (1983). Teaching and training styles and strategies - 
The Relationship between Iranian EFL Teacher's Emotional Intelligence...

Paradigmatic approach by video. Westwood, P. (2008). What teachers need to Education Tribune Libre, Probio Revue, $2 . \quad$ know about teaching methods. ACER Press 
Mohammad Ali Ayatollahi, Fatemeh Ferdosi 